\title{
I. On alpha- and beta-orcine
}

\section{John Stenhouse Esq. Ph.D.}

To cite this article: John Stenhouse Esq. Ph.D. (1848) I. On alpha- and beta-orcine , Philosophical Magazine Series 3, 33:219, 1-7, DOI: 10.1080/14786444808646036

To link to this article: http://dx.doi.org/10.1080/14786444808646036

$$
\text { 册 Published online: } 30 \text { Apr } 2009 .
$$

Submit your article to this journal

LII Article views: 3

Q View related articles ¿ 
THE

\title{
LONDON, EDINBURGH AND DUHLIN \\ PHILOSOPHICAL MAGAZINE
}

\author{
A N D \\ JOURNAL OF SCIENCE. \\ [THIRD SERIES.] \\ JULY 184.8.
}

\author{
I. On Alpha- and Beta-Orcine. \\ By John Stenhouse, Esq., Ph.D.*
}

\begin{abstract}
A PAPER on the lichens, read before the Royal Society $A$ about three months ago, contained among other matters some observations upon orcine, and described an easy method of procuring that interesting substance in a perfectly colourless state. In the present notice, I purpose narrating a few observations $I$ have subsequently made, and to describe a new species of orcine derived from usnic acid, to which I have given the provisional name of beta-orcine.
\end{abstract}

The usual mode of preparing alpha-orcine is by boiling lecanoric, erythric, or any of the similar principles of the lichens, with an excess of lime or baryta. The orcine obtained in this way is always more or less coloured. $\quad \mathbf{W}^{\prime}$ ithout entering into the minute details of the process for preparing the colourless orcine, which are fully given in the paper already referred to, I only remark in passing, that it may be readily procured by boiling the alpha- and beta-orsellesic, or the erythrelesic acids, in pure water from half an hour to an hour, when a great deal of carbonic acid is given off; and on the solutions being concentrated and set aside, abundance of crystals of colourless orcine are deposited. If a little animal charcoal is kept in the solution while it is being concentrated, it will be found useful in preventing any tendency to oxidation.

A quantity of colourless orcine prepared in this way was dried at the ordinary temperature, and analysed with chromate of lead. $0.332 \mathrm{grm}$. substance dried at $60^{\circ} \mathrm{F}$. gave 0.717 carbonic acid and 0.204 water.

* Communicated by the Author.

Phil. Mag. S. 3. Vol. 33. No. 219. July 1848. 


\begin{tabular}{ccccc}
\multicolumn{5}{c}{ Orcine dried at $60^{\circ} \mathrm{F}}$. \\
$21 \mathrm{C}$ & 1605.135 & 59.61 & 58.90 & $\begin{array}{c}\text { Mr. Schunck } \\
\text { found }\end{array}$ \\
$15 \mathrm{H}$ & 187.192 & 6.95 & 6.82 & 7.06 \\
$9 \mathrm{O}$ & 900.000 & 33.44 & $\frac{34.28}{100.00}$ & $\frac{33.96}{100.00}$
\end{tabular}

It will be observed that this analysis agrees pretty closely with Mr. Schunck's, and that the small amount of colouring matter remaining in orcine prepared by the old method has no perceptible effect upon the result of the analysis.

Orcine is a body which retains its water of crystallization with great tenacity. It may be rendered anhydrous, however, in several ways, as when it is distilled, when it is heated to $212^{\circ} \mathrm{F}$., and, as I have recently found, when it has been repeatedly crystallized out of æther, or even when it has been dried in vacuo over sulphuric acid.

The last-mentioned mode of rendering orcine anhydrous, though tedious, requiring from three to six weeks, is by far the best and safest, as the orcine remains perfectly colourless, and all risk of decomposition is avoided. The following are the results of several analyses of culourless orcine, prepared from alpha-orsellesic acid at four different times, and dried in vacuo.

I. $0.264 \mathrm{grm}$. substance gave $0.6610 \mathrm{CO}^{2}$ and 0.1570 water.

II. $0.349 \mathrm{grm}$. substance gave $0.8675 \mathrm{CO}^{2}$ and 0.205 water.

III. $0.324 \mathrm{grm}$. substance gave $0.8085 \mathrm{CO}^{2}$ and 0.1985 water.

IV. 0.2064 old orcine, also dried in vacuo, gave $0.515 \mathrm{CO}^{2}$ and $0 \cdot 130$ water.

\begin{tabular}{|c|c|c|c|c|c|c|}
\hline & $\begin{array}{c}\text { Calculated } \\
\text { numbers. } \\
1605 \cdot 135\end{array}$ & $\begin{array}{c}\text { Anbydrous } \\
\text { orcine. } \\
68 \cdot 16\end{array}$ & $\begin{array}{c}\text { I. } \\
68 \cdot 28\end{array}$ & $\begin{array}{c}\text { II. } \\
67 \cdot 80\end{array}$ & $\begin{array}{c}\text { HI. } \\
68.05\end{array}$ & $\begin{array}{l}\text { IV. } \\
68.02\end{array}$ \\
\hline & $149 \cdot 754$ & 6.35 & 6.60 & 6.52 & 6.70 & 6.97 \\
\hline & $600 \cdot 000$ & $25 \cdot 49$ & $25 \cdot 12$ & $25 \cdot 68$ & $25 \cdot 25$ & $25 \cdot 01$ \\
\hline & & & 0.00 & $00 \cdot 00$ & 00 & $00 \cdot 0$ \\
\hline
\end{tabular}

I. and II. analyses were made with chromate of lead, and the heat strongly raised towards the close of the combustion. No. III. was burned with pure oxide of copper, assisted with a current of oxygen gas. No. IV. was orcine prepared by the old process, and also dried in vacuo: it too was burned with oxide of copper, assisted by a current of oxygen. It is observable, that the quantity of hydrogen in the two last analyses is too high: the reason of this is, that from fear of decomposing the orcine, I did not venture to heat the mixture of the 
substance and oxide of copper in the tube, and then to dry it with an exhausting syringe, as is usually done.

It is plain from the result of these analyses, that anhydrous orcine has lost three atoms of water, and that its probable formula is $\mathrm{C}_{21} \mathrm{H}_{12} \mathrm{O}_{6}$, that of hydrated orcine being $\mathrm{C}_{21} \mathrm{H}_{15} \mathrm{O}_{9}$.

I subjoin the results of previous experimenters on anhydrous orcine, with which it will be seen that these analyses agree pretty closely.

Dumas. Schunck. Robiquet. Distilled orcine. Dried at $212^{\circ}$ F. Distilled orcine.

\begin{tabular}{|c|c|c|}
\hline $\begin{array}{l}\text { Carbon } \\
\text { Hydrogen } \\
\text { Oxygen }\end{array}$ & $\begin{array}{r}67 \cdot 78 \\
6 \cdot 50 \\
25 \cdot 72\end{array}$ & $\begin{array}{r}67.88 \\
6.60 \\
25.52\end{array}$ \\
\hline & 100.00 & $100 \cdot 00$ \\
\hline
\end{tabular}

In order to corroborate this determination of the atomic weight of orcine, which, it must be confessed, still remains somewhat doubtful, I made repeated attempts to prepare the lead salt previously described both by Dumas and Schunck, but I am sorry to say with by no means satisfactory results. This perhaps is not to be wondered at, when we consider how easily alterable orcine is. In my first trials, I treated an aqueous solution of orcine with a very slight excess of subacetate of lead. The precipitate in the course of a few minutes assumed a deep red colour, and the compound appeared so unstable, that much of the orcine was removed by the washwater ; so that the more the precipitate was washed, the greater was the amount of oxide of lead it contained. In some subsequent trials, when the quantity of subacetate of lead which was added was not sufficient to precipitate the whole of the orcine in the solution, the precipitate, though reddish-coloured, was not nearly so deeply coloured as when a slight excess of base had been employed. The amount of oxide of lead in these precipitates was however greatly diminished; and though frequently repeated, 1 never could get the results of the various trials to agree in a satisfactory manner. Mr. Schunck admits that his experiments were somewhat similar. I subjoin the results of a few of my experiments.

I. Orcine precipitated by a slight excess of subacetate of lead, 1.305 grm. salt gave $0.4 .67 \mathrm{PbO}$ and $0.525 \mathrm{~Pb}=1.081$ $\mathrm{Pl} \mathrm{O}=82 \cdot 83 \mathrm{PbO}$ per cent.

II. Where part of the orcine remained in solution, 0.773 salt gave $0.1383 \mathrm{PbO}$ and $0.371 \mathrm{~Pb}=0.5379 \mathrm{PbO}=69.58$ $\mathrm{PbO}$ per cent.

1II. Prepared in the same way, but at a different time, 0.667 salt gave $0.200 \mathrm{PbO}$ and $0.231 \mathrm{~Pb}=0.4488 \mathrm{PbO}=67.28$ per cent. 


\section{Examination of the Crystalline Form of Orcine.}

I transmitted a quantity of crystallized orcine to Professor W. H. Miller of Cambridge, who has kindly favoured me with the subjoined determination of its crystalline form.

Oblique. Symbols. a 100, $c$ 001, e 101, $m 110$.

Orcine.

Angles between normals to the faces.

$\begin{array}{llll}a e & 43 & 4 \dot{4} \\ a c & 83 & 57 \\ m a & 51 & 12 \\ m m^{\prime} & 77 & 36\end{array}$

Cleavage parallel to $a$, very perfect.

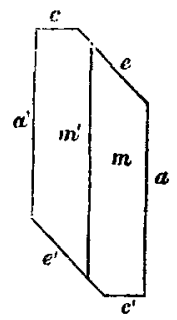

\section{Beta-Orcine.}

The substance to which I have given the name of betaorcine is obtained from usnic acid, which is perhaps the most widely diffused of all the known proximate principles of the lichens. Knop found usnic acid in several species of Usnea, such as Usnea florida, U. hirta, and U. plicata. Messrs. Rochleder and Heldt extracted it from the lichen Rangeferinus, Usnea barbata, and Ramalinea calicaris. In addition to these sources, I have found it in the Evernia Prunastri and in $\mathrm{Ra}$ malinea Fraxinia. The best mode of extracting usnic acid, as I have fully detailed in the paper already referred to, is by macerating the lichens in milk of lime, and precipitating the filtered solution by muriatic acid.

Beta-orcine may be obtained from usnic acid by several processes. The method which I have found most convenient is by subjecting the crude usnic acid, previously dried, to destructive distillation. The beta-orcine sublimes, and is deposited in long yellow crystals, partly on the neck and sides of the retort; but by much the larger portion of it is dissolved in a brownish-coloured resinous liquid which passes into the receiver. A very large quantity of a bulky porous charcoal remains in the retort.

The resinous fluid which has passed into the receiver must be repeatedly treated with considerable quantities of boiling water to dissolve out the orcine, which is retained by the resin with great pertinacity. The solutions containing the impure orcine should be concentrated to the consistence of a syrup, and left standing for some time in a flat open vessel. In the 
course of a day or two the liquid becomes filled with a mass of brownish-coloured crystals, which must be collected and pressed between folds of blotting-paper to free them from adhering resin and colouring matter.

The crystals must be further purified by digestion with animal charcoal, and by being repeatedly crystallized out of water: they then form hard, slender, brittle prisms, which still retain a faintish yellow shade, and are about half an inch long. In order to obtain beta-orcine perfectly white, it must be crystallized out of weak spirits, assisted, as before, by a little animal charcoal. So soon as the crystals are all deposited, they should be removed from the solution and dried on blottingpaper, as the mother-liquor, on standing for some time, becomes reddish-coloured. Beta-orcine crystallizes out of weak spirits in larger and more regular crystals than those obtained from its aqueous solutions. It forms fonr-sided prisms, surmounted at either end by well-defined four-sided pyramids. 'These crystals are hard and brittle, have a brilliant lustre, and are from an inch to three-quarters of an inch long. I am indebted to Professor W. H. Miller of Cambridge for the subjoined measurement of their angles.

Pyramidal. Symbols. a 100, $c$ 001, $m 110, s 101, x$ 201, $r 111$.

Angles between normals to the faces.

$\begin{array}{llr}a a^{\prime} & \mathbf{9 0} & \mathbf{0} \\ a c & 90 & 0 \\ m a & 45 & 0 \\ s c & 49 & 3 \\ x c & 66 & 33 \\ r c & 58 & 29 \\ x a & 23 & 27 \\ s a & 40 & 57 \\ r m & 31 & 31 \\ r a & 52 & 56 \\ r s & 37 & 4 \\ x r & 40 & 27 \\ x m & 49 & 33\end{array}$

No cleavage observable.

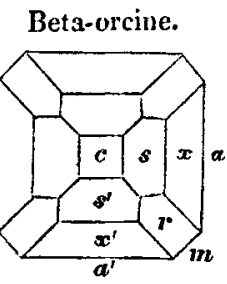

Beta-orcine, like ordinary orcine, to which in so many respects it bears a very close analogy, may be also obtained by boiling usnic acid with an excess either of caustic potash or of lime or baryta. By none of these methods, however, is it so readily procured as by destructive distillation. By much the larger portion of the usnic acid is converted by the potash into an acid resin, with which the alkali combines; the free alkali is also apt to destroy most of the orcine as it is formed. 
When usnic acid is boiled with lime or baryta, the excess of base is removed by a current of carbonic acid gas, and the clear liquor evaporated to dryness on the water-bath. The dried mass is then to be agitated with æether; and on the evaporation of the æther, the beta-orcine is deposited in nearly colourless crystals.

Beta-orcine is tolerably soluble in cold water, though not nearly so much so as alpha-orcine, but very soluble in boiling water. It is very soluble in alcohol and in æther. It has a faint but distinctly sweetish taste. It has no reaction upon test-paper, and is a perfectly neutral body. When heated, it sublimes without leaving any residue. The smell of its vapours is suffocating. It inflames readily, and burns with a strong smoky flame.

In the course of a few minutes it assumes, with ammonia, a beautiful blood-red colour, which on standing becomes deeper. Beta-orcine is much more rapidly acted on by ammonia than alpha-orcine. The colour which alpha-orcine yields with ammonia is reddish-brown. When left in contact with caustic or carbonate of potash, beta-orcine yields a beautiful reddish-purple dye stuff. This appears to be the same amorphous red body which Knop observed when preparing usnate of potash, without, however, his remarking the source which produced it. The smallest portion of beta-orcine instantly strikes a bright blood-red colour, with a solution of hypochlorite of lime; just as alpha- and beta-orsellic and erythric acids do with the same reagent. Alpha-orcine, on the other hand, yields a purple violet colour with hypochlorite of lime.

The crystals of beta-orcine, when dried in the air and then in vacuo over sulphuric acid, do not lose any water. The four following analyses were made with beta-orcine prepared on four different occasions: they were all dried in vacuo:-

I. 0.317 grm. orcine burnt with chromate of lead, gave. $0.8002 \mathrm{CO}^{2}$ and 0.209 water.

II. $0.391 \mathrm{grm}$, orcine burnt with chromate of lead, gave $0.985 \mathrm{CO}^{2}$ and 0.254 water.

III. 0.2608 grm. orcine burnt with chromate of lead, gave $0.657 \mathrm{CO}^{2}$ and 0.173 water.

IV. $0.3138 \mathrm{grm}$. orcine burnt with chromate of lead, gave $0.800 \mathrm{CO}^{2}$ and 0.212 water.

\begin{tabular}{|c|c|c|c|c|c|c|}
\hline \multirow{4}{*}{$\begin{array}{l}38 \mathrm{C} \\
24 \mathrm{H} \\
10 \mathrm{O}\end{array}$} & \multicolumn{2}{|c|}{ Calculated numbers. } & \multirow{2}{*}{$\begin{array}{c}\mathrm{J} . \\
68 \cdot 84\end{array}$} & \multirow{2}{*}{$\begin{array}{l}\text { II. } \\
68 \cdot 70\end{array}$} & \multirow{2}{*}{$\begin{array}{l}\text { III. } \\
68 \cdot 70\end{array}$} & \multirow{2}{*}{$\begin{array}{c}\text { IV. } \\
69 \cdot 20\end{array}$} \\
\hline & & $69 \cdot 08$ & & & & \\
\hline & & & & & & \\
\hline & 1 & & & & & \\
\hline & & & & & & \\
\hline
\end{tabular}


These analyses give $\mathrm{C}_{38}, \mathrm{H}_{24}, \mathrm{O}_{10}$ as the formula for betaorcine: it is, however, perfectly empirical. When beta-orcine, previously dried in vacuo, was heated in the water-bath to $212^{\circ} \mathrm{F}$, it parted with a considerable amount of water. The orcine did not become in the least degree coloured, neither did it melt, though the temperature was raised to $230^{\circ} \mathrm{F}$. Alpha-orcine melts and becomes coloured at $212^{\circ} \mathrm{F}$. A quantity of beta-orcine, which had been kept four weeks in the water-bath at $212^{\circ} \mathrm{F}$., had lost nearly 30 per cent.. in weight, and was still continuing to lose weight. This however did not arise merely from the loss of water, but because a considerable portion of the orcine itself had volatilized even at the comparatively low temperature of $212^{>} \mathrm{F}$. The quantity of water which beta-orcine contains cannot therefore be determined by drying it on the water-bath.

I have been unable to determine the atomic weight of betaorcine. It gives no precipitate with nitrate or ammonionitrate of silver, with the salts of iron, baryta and copper, or with neutral acetate of lead. It yields a pretty abundant whitish precipitate with subacetate of lead, which is soluble in an excess of the precipitant. This precipitate is exceedingly alterable, and immediately becomes deep red-coloured, even more rapidly than is the case with alpha-orcine in similar circumstances.

Glasgow, May 22, 1848.

\section{On the Theory of Nobili's Coloured Rings. By E. DU Bors-Reymond and W. Beetz*. \\ I.}

NOBILI first pointed out the possibility of applying the 1 coloured films (apparenze elettro-chimice) which he discovered, to determine the diffusion of the current in nonprismatic conductorst. But with his unacquaintance of Ohm's law of the motion of electricity, even according to one dimension, he was unable to give proper evolution to this idea. In a treatise entitled Note sur les anneaux produits par le dépôt des oxydes métalliques sur les métaux $\$$. M. Edmond Becquerel attempted to subject the simplest form of Nobili's rings to a rigid investigation, both in an optical and electrical point of view. The rings were obtained by a method given by M. Becquerel, senior, viz. by pouring a thin layer of a solution of oxide of

- Read before the Physical Society of Berlin, on the 11th Dec. 1846, and communicated by the Authors.

+ Bibliothèque Universelle de Genive. Anc. Sér. Sc. et Arts, 1835, t. lix. pp. $263,416$.

$\ddagger$ Annales de Chimie et de Physique. Janvier 1845, 3 ser. t. xviii. p. 342 . 